\title{
Physical Therapist Assistants' Perceptions of the Documented Roles of the Physical Therapist Assistant
}

Background and Purpose. This study investigated physical therapist assistants' (PTAs) perceptions of the documented roles of PTAs and compared those perceptions with those of physical therapists from a previous study. Subjects and Methods. A questionnaire that described 79 physical therapy activities was distributed to a sample $(n=400)$ of PTAs derived from the American Pbysical Therapy Association membership. The response rate was 56\% $(n=225)$. Respondents indicated whether each activity was included in the documentation describing PTA roles. Discriminant analyses were used to determine whether demographic factors predicted the pattern of responses. In addition, meta-analytic techniques were used to determine whether PTA responses were different from those of physical therapists gathered previously. Results. The greatest agreement of PTA opinions with published guidelines occurred for treatment implementation activities, and the lowest level of agreement occurred for items designated as administrative activities. Responses of PTAs were different from those of physical therapists on 21 of the 79 activities. The greatest number of these differences occurred for evaluative functions $(n=9)$. Physical therapist assistants' perceptions of documented PTA roles uere generally less consistent with published guidelines than were those of physical therapists. Conclusion and Discussion. Physical therapist assistants perceptions of the roles of the PTA were, for some activities, not consistent with uritten guidelines. Using the data provided in this study, discussions to revise the documentation of the scope of PTA practice may focus on those activities for which disagreement between PTAs and physical therapists exists and for which opinions differ markedly from published guidelines. (Robinson AJ, DePalma MT, McCall M. Physical therapist assistants perceptions of the documented roles of the physical therapist assistant. Phys Ther. 1995; 75:1054-1066J

Key Words: Physical therapist assistant, Professional roles, Role, Supportive personnel.
AJ Robinson, PhD, PT, is Asscociate Professor, Department of Physical Therapy, School of Health Sciences and Human Performance, Ithaca College, 339 smiddy Hall, Ithaca, NY I 4850 (USA) (RobbyGithaca,edu). Address all correspondence to Dr Robinson.

MT DePalma, PhD, is Assistant Professor, Department of Psychology, School of Humanities and Sciences, Itluaca College.

M McCall, PhD, is Associate Professor, Department of Psychology, School of Humanities and Sciences, Ithaca College.

This study was approved by the Human Subjects Review Committee of thaca College.

\section{Andrew J Robinson Mary Turner DePalma Michael McCall}

Physical therapist assistants (PTAs) have been paraprofessional members of the physical therapy community for nearly 25 years. The growth in numbers of individuals working as PTAs has outpaced that of most other allied health service careers. ${ }^{1}$ In the early 1980 s, nearly 50 PTA education programs graduated approximately 700 PTAs annually. In 1993, more than 140

This article was submitted September 13, 1994, and was accepted Auglust 4. 1995 
education programs produced approximately 2,550 PTA graduates. 2 As a result, it has been estimated that more than 17,000 PTAs are actively involved in the delivery of physical therapy services. ${ }^{3}$ By virtue of their numbers, PTAs appear to play an important role in maximizing the availability of physical therapy services to the public during a time when the demand for such services cannot be met by physical therapists (PTs) alone. Increases in the numbers of PTAs have been accompanied by an expansion of their clinical roles and responsibilities and modifications in guidelines outlining PTA functions

\section{Resources Describing the Roles of the Physical Therapist Assistant}

Several documents of the American Physical Therapy Association (APTA) as well as interpretive articles in the professional literature can be used to formulate a picture of the scope of PTA practice. One important document that provides insight into PTA practice is Evaluative Criteria for ACcreditation of Education Programs for the Preparation of Physical Therapist Assistants. ${ }^{4}$ Standard VI of this document, applicable from 1978 through mid-1994, placed emphasis on 10 specific treatment implementation activities, which were mainly physical agent or modality oriented. Only two procedures associated with the evaluative process were specified in the standard: the performance of goniometric measurement and the identification of architectural barriers. This document was revised in $1993^{5}$ and became effective in July 1994 (several months after the completion of the data-collection phase of the present study). The new accreditation criteria expanded the treatment functions of the PTA and presented 12 assessmentand measurement-related activities as PTA clinical roles (ie, "... perform ... assessment and measurement techniques ... [related to]: architectural barriers and environmental modification, endurance, flexibility/joint ROM [range of motion] and muscle length, functional activities, gait and balance, pain, posture, righting and equilibrium reactions, segmental length, girth and volume, strength vital signs ..."5). A comparison of the treatment and evaluative activities in the new accreditation criteria (sections 3.2.2.2 and 3.2.2.4, respectively) with those identified in the evaluative criteria for PT programs $^{6}$ (sections 4.1.5.1 and 4.1.3.2, respectively) reveals that the new performance expectations of PTA graduates are a subset of those identified for the recently graduated PTs. The latest revision of this document outlining PTA roles ${ }^{5}$ reflects an increase in the scope of practice of PTA program graduates.

A second major document describing PTA roles has been APTA's House of Delegates (HOD) policy on the definition and utilization of the PTA. ${ }^{7}$ Three versions of this policy have existed since 1981. The policy adopted in 1981 (HOD-06-81-13-45) identified specific functions of the PTA that included both treatment implementation and evaluative activities. In addition, nine types of activities in evaluation, treatment planning, and administration were designated as the responsibility of the PT. The most recent version of this policy (approved in 1993) no longer lists specific PTA activities, but does include a statement regarding those physical therapy activities that are not to be performed by the PTA. The current HOD policy leaves delegation of tasks to the PTA largely up to the discretion of the supervising PT. Thus, although the evaluative criteria for PTA education programs have become more explicit with respect to PTA roles, revisions in the HOD definition and utilization statements have become less explicit in their description of the clinical roles of the PTA.

Other documents that serve to differentiate between PT and PTA roles include Competencies in Physical Therapy: An Analysis of Practice (the "Red Book"), first published in 1977"; Standards of Ethical Conduct for the Physical Therapist Assistant'; Guide for Ethical Conduct of the Affiliate Member ${ }^{10}$; and articles in the professional literature. ${ }^{11-14}$

\section{Independent Research on the Role of the Physical Therapist Assistant}

Despite the increasing impact of PTAs on the delivery of physical therapy services, little research has been reported regarding their roles and responsibilities. The literature on this topic published between 1973 and 1992 has been reviewed in detail previously ${ }^{15}$ and no other research has appeared on this topic. For example, two studies reported in the early to mid-1970s ${ }^{16,17}$ used survey methods to investigate PTA performance of clinical tasks. Both of these studies suffered from methodological shortcomings such as small sample size or failure to demonstrate reliability of the survey instruments. In addition, these studies were performed at a time when PTAs had been involved in physical therapy service for only a few years. These and other factors make the interpretation of these early findings difficult, and the results may not be relevant to current PTA practice.

Schunk et al ${ }^{18}$ concluded from their survey data that PTs do not utilize PTAs to their full potential in the implementation of physical therapy services and that PTs may not clearly understand their supervisory responsibilities in the delegation of clinical tasks to the PTA.

Robinson and colleagues, ${ }^{15}$ however, found that PTs' opinions regarding the roles of the PTA were generally consistent with existing guidelines. That study also revealed that the potential existed for either utilization of the PTA in activities beyond the documented scope of practice (overutilization) or, in other cases, the potential for failure of PTs to assign activities consistent with defined roles (underutilization). Such perceptions of PTA roles did not, in general, change over the period between 1986 and 1992

\section{Purpose}

We have previously investigated PTs' perceptions of PTA roles. The purpose of this study was to investigate PTAs perceptions of the documented roles 
of the PTA according to those guidelines in effect at the time of data collection. In addition, this study compared PTAs' perceptions of PTA roles with those of PTs who previously participated in a similar study. ${ }^{15}$

\section{Method}

\section{Sample}

A questionnaire was mailed in the spring of 1994 to a sample $(n=400)$ of PTAs derived from the APTA membership. To select the sample, the total number of PTA members of APTA was divided by 400 . The PTA members were then soited by their state affiliation, and every nth person was then selected from the sorted list in order to obtain the desired sample size. The number of PTAs selected from each state was therefore proportional to the total number of PTA members of each state in early 1994 The sample represented PTAs who were members of APTA and not all PTAs currently in practice.

\section{Instrumentation}

A questionnaire consisting of 89 items was developed in a previous study. ${ }^{15}$ Seventy-nine of the items identified physical therapy activities. Respondents were asked to indicate whether the task was included in the role of the PTA as outlined by written guidelines on PTA practice or the professional literature. Alternatively, the respondent could mark "Do not know."

The last 10 items were included to gather demographic information on the responclents as well as information on the level of (1) PT supervision, (2) performance of initial evaluations, (3) independent planning of treatment programs, and (4) independent establishment of treatment goals.

Complete details on questionnaire development are presented in Robinson et al. ${ }^{15}$ It is important to note that
Robinson et al ${ }^{15}$ found that the internal reliability of the survey instrument was quite high (Cronbach's alpha=.93) as was the test-retest reliability $(r=83)$. Thirteen physical therapists were asked to place each of the 79 activity items into one of four categories (evaluation, treatment planning, treatment implementation, and aclministrative). ${ }^{15}$ Three of these categorics exhibited substantial internal reliability (Cronbach's alpha=.73-89). The fourth category, treatment planning, exhibited weak internal reliability (Cronbach's alpha $=.47$ ). This categorization of items was performed solely for the purposes of data presentation.

\section{Procedure}

A cover letter requested that the questionnaire be completed and returned in an accompanying stamped, selfaddressect envelop within 4 weeks of the date of mailing. Approximately 10 days after mailing the questionnaires, a follow-up postcard was sent to each P'TA on the distribution list asking the PTA to complete and return the questionnaire if he or she had not already done so.

\section{Data Analysis}

We coded the responses from the returned questionnaires, entered the coded responses into data files, and processed the data using SPSS-X software." This program allowed us to calculate frequency clatal and use discriminant analyses to assess the role of demographic and occupational factors in predicting survey item responses. For each of these analyses, one canonical discriminant function was calculated and the associated Wilk's lambda, chi-square, and significance values were calculated.

To make the necessary comparisons between responses from the present PTA sample and the 1994 PT sample, a series of data-management strategies were used. First, given that the response format for each of the samples was categorical, the use of nonparametric analytic techniques was required. For each of the samples, separate chi-square analyses were performed on each of the 79 activity items. To make the intended comparisons between the independent samples, it was necessary to transform the chi-square statistic to a common metric. Fortunately, advances in metaanalytic techniques ${ }^{19}$ provide the method for transforming the chisquare into a product-moment correlation using the following formulat from Table $F$ of Glass et al ${ }^{1 \%(p 150)}$.

$$
r_{x y}=\left[\chi^{\left.2 /\left(\chi^{2}+n\right)\right]^{1 / 2}}\right.
$$

Next, a standard transformation table was used to convert the obtained $r$ values to Fisher $z$ values. It is important to note that the transformed Fisher $z$ value is sample-based and not equivalent to a standard $Z$ distribution. ${ }^{20}$ Once the Fisher $z$ values were obtained, it was then possible to test the significance of the difference between these tabled $z$ values using the following formula ${ }^{20\left(p_{2} 27\right)}$ :

(2) $\mathrm{Z}=z_{1}-z_{2} /\left[1 /\left(\mathrm{n}_{1}-3\right)+1 /\left(\mathrm{n}_{2}-3\right)\right]^{1 / 2}$

Finally, the probability value associated with the resultant $Z$ value was obtained from the standard $Z$ table. In orcler to maintain the familywise error rate for all comparisons at the .05 level, a Bonferroni correction was applied, and corrected probability values $^{21}$ are reported.

\section{Results}

\section{Response Rate}

Fifty-six percent $(n=225)$ of the 400 distributed questionnaires were completed and returned. Five questionnaires $(2 \%)$ were returned by the postal service and marked as undeliverable. All returned responses were sufficiently completed to be usable in subsequent data analyses.

\section{Characteristics of Respondents}

The characteristics of respondents participating in this study are summa- 
Table 1. Information on Respondents $(n=225)$

$\begin{array}{ll}\text { Characteristic } & \text { Percentage of }^{\text {PTAs }^{\text {a }}}\end{array}$

\begin{tabular}{|c|c|}
\hline \multicolumn{2}{|l|}{ Gender } \\
\hline Female & 86 \\
\hline Male & 14 \\
\hline \multicolumn{2}{|l|}{ Highest earned degree } \\
\hline Associate's & 81 \\
\hline Bachelor's & 17 \\
\hline Master's & 2 \\
\hline Doctorate & 0 \\
\hline \multicolumn{2}{|l|}{ Years in practice } \\
\hline$<4 y$ & 39 \\
\hline $4-6 y$ & 28 \\
\hline $7-9 y$ & 12 \\
\hline $10-12 y$ & 7 \\
\hline$>12 y$ & 14 \\
\hline \multicolumn{2}{|l|}{ Type of facility of current practice } \\
\hline General hospital & 24 \\
\hline Home & 8 \\
\hline Rehabilitation & 16 \\
\hline Private & 19 \\
\hline Other ${ }^{b}$ & 33 \\
\hline \multicolumn{2}{|c|}{$\begin{array}{l}\text { Are your current clinical activities supervised } \\
\text { by a physical therapist? }\end{array}$} \\
\hline Yes-for all patients & 71 \\
\hline Yes_for most patients & 15 \\
\hline Yes-for a few patients & 8 \\
\hline No-activities not supervised & 6 \\
\hline \multicolumn{2}{|c|}{$\begin{array}{l}\text { In your professional education program, was information on the } \\
\text { scope of the PTA practice included in the curriculum? }\end{array}$} \\
\hline Yes & 94 \\
\hline No & 4 \\
\hline Do not know & 2 \\
\hline
\end{tabular}

"PTA = physical therapist assistant.

"Includes individuals who indicated practice in more than one type of facility as well as school systems, extended care facilities (skilled nursing), or industrial clinics.

rized in Table 1 . The typical respondent in this study was a female PTA holding an associate's degree as the highest earned academic degree with less than 6 years' clinical practice. Nearly one third of the respondents identified a practice setting other than general hospital, home health agency, rehabilitation facility, or private practice. The group identified in Table 1 as "other" included individuals who indicated practice in more than one type of facility as well as school systems, extended care facilities (skilled nursing), or industrial clinics.

\section{Responses on Physical Therapist Assistant Roles in Evaluation Activities}

The responses of PTAs to P'TA evaluative procedure items $(n=24)$ are summarized in Table 2, along with the percentage of responses of PTs to the identical items in a previous study performed in the fall of $1992 .{ }^{15}$ Analy- ses revealed that patterns of responses were different between PTAs and PTs for 9 of the 24 items.

The first six items listed in Table 2 were designated as tasks consistent with guidelines on PTA practice. 4, 5,7-14 For this group of activities, the most notable finding was that about one half of the PTAs did not believe that performance of evaluative tests for joint ROM was a documented role of the PTA. In addition, the distribution of responses for PTs in a previous study was not different for this item. Physical therapist and PTA responses were different for the activity "monitor vital signs." Although statistically different, the difference in distributions of responses between PTAs and PTs on this item is not particularly meaningful as the significant chi-square value resulted from the restricted range at the upper limits of the distribution.

The remaining 18 evaluative activities listed in Table 2 were not explicitly identified as PTA roles in reference documents. ${ }^{4,5-1+}$ Perceptions of PTAs and PTs differed for 8 of these 18 evaluative activities ("determine prosthetic/orthotic/assistive device," "interpret joint integrity tests," "interpret developmental tests," "test accessory motion joints," "interpret joint ROM tests," "perform specific manual muscle testing," "assess muscle tone," and "determine wheelchair type/features"). In summary, a greater percentage of PTAs than PTs viewed these evaluative functions as consistent with the documented scope of PTA practice.

\section{Responses on Physical Therapist Assistant Roles in Treatment Planning}

The responses of survey participants to PTA performance of 14 treatment planning activities are summarized in Table 3. Analyses revealed that P'TA and $\mathrm{PT}$ responses were different for 4 of these activities ("develop therapeutic exercise program," "select ultrasound method/settings," "design activities of daily living [ADL] plan of care," and "plan massage method/technique"). The apparent difference in responses for the activity "prepare 
Table 2. Comparison of Responses to Patient Evaluation Items ${ }^{a}$

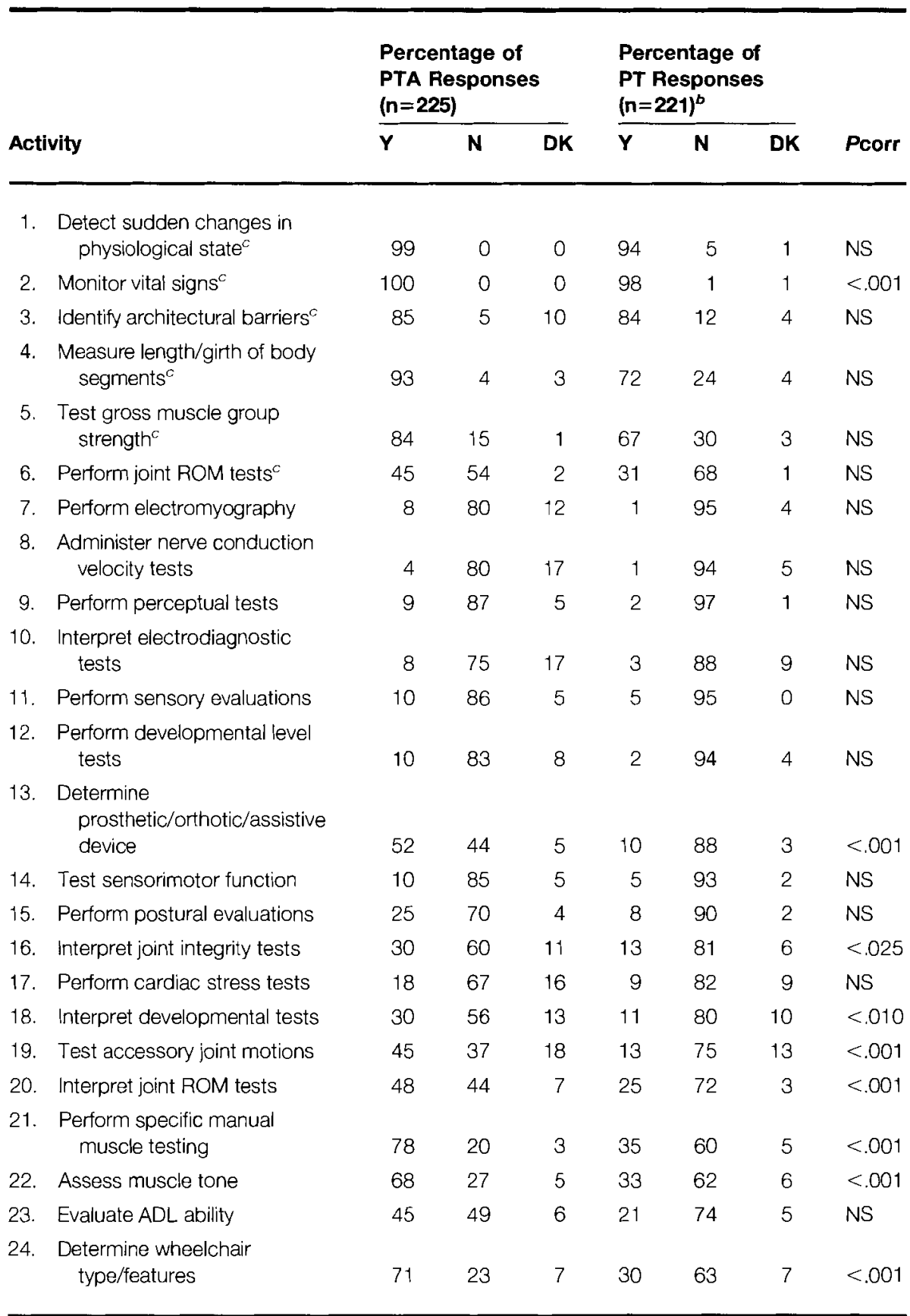

"Y=yes, designated physical therıpist assistant (PTA) role; $\mathrm{N}=\mathrm{no}$, not designated PTA role; $\mathrm{DK}=$ do not know. Responses rounded to nearest whole percentage; missing vilues disregarded. $\mathrm{ROM}=$ range of motion; $\mathrm{ADL}=$ activities of daily living; NS= not significant.

'Thysical therapist (PT) responses from Robinson et al."

"Tdentified in reference documents as a PTA role

patient, equipment, treatment area" is not remarkable because the significant chi-square value resulted from the restricted range at the upper limits of the distribution.

The first 11 items listed in Table 3 have not been identified in reference documents ${ }^{4,5,7-14}$ as PTA roles, whereas the last 3 items were consistent with published guidelines. Higher percentages of PTAs than PTs viewed the first 11 treatment planning functions as consistent with PTA guidelines. There was a difference in distribution of responses for the activities "develop therapeutic exercise program," "select ultrasound method/ settings," "design ADL plan of care," and "plan massage method/technique." In these instances, between $52 \%$ and $76 \%$ of the PTAs indicated that these 4 treatment planning tasks were consistent with PTA guidelines, whereas only about one quarter to one third of the PTs shared this perspective.

\section{Responses on Physical Therapist Assistant Roles in Treatment Implementation Activities}

Twenty-five items included in the questionnaire described treatment implementation activities. The responses of survey participants to PTA performance of treatments are summarized in Table 4 . The distribution of responses for only 2 treatment activity items ("measure/fit compression garments" and "administer therapeutic heat/cold") were found to be different between PTAs and PTs. The apparent difference of opinion on administration of heat and cold is not meaningful because the significant chi-square value once again resulted from the restricted range at the upper limits of the distribution. For the activity "measure/fit compression garments," about two thirds of the PTAs viewed this as a documented PTA function, whereas only one third of the P'Ts shared this perspective.

Twenty of the items listed in Table 4 were identified as PTA roles in resource documents. In contrast, performance of sensory stimulation for reeducation, perceptual training, neurodevelopmental treatment, oral sensorimotor treatment, and measure and fit of compression garments were not explicitly identified in references as activities of the PTA. For the first three of these items ("perform sensory reeducation stimulation," "perform perceptual training," and "administer neurodevelopmental treatment sessions"), response distributions were nearly identical for both PTAs and PTs, with both groups believing that these activities were within the scope of documented PTA practice although they have not been identified as such. 
Table 3. Comparison of Responses to Treatment Planning Items ${ }^{a}$

\begin{tabular}{|c|c|c|c|c|c|c|c|}
\hline \multirow[b]{2}{*}{ Activity } & \multicolumn{3}{|c|}{$\begin{array}{l}\text { Percentage of } \\
\text { PTA Responses } \\
(n=225)\end{array}$} & \multicolumn{3}{|c|}{$\begin{array}{l}\text { Percentage of } \\
\text { PT Responses } \\
(n=221)^{b}\end{array}$} & \multirow[b]{2}{*}{ Pcorr } \\
\hline & $\mathbf{Y}$ & $\mathbf{N}$ & DK & $\mathbf{Y}$ & $\mathbf{N}$ & DK & \\
\hline 1. Design patient plan of care & 16 & 83 & 0 & 5 & 92 & 3 & NS \\
\hline $\begin{array}{l}\text { 2. Change PT goals/treatment } \\
\text { techniques }\end{array}$ & 31 & 68 & 1 & 8 & 91 & 1 & NS \\
\hline $\begin{array}{l}\text { 3. Select traction } \\
\text { methods/settings }\end{array}$ & 22 & 75 & 3 & 10 & 88 & 2 & NS \\
\hline $\begin{array}{l}\text { 4. Select electrotherapy } \\
\text { method/settings }\end{array}$ & 37 & 60 & 3 & 16 & 81 & 3 & NS \\
\hline 5. Set short-/long-term goals & 24 & 74 & 2 & 10 & 87 & 3 & NS \\
\hline $\begin{array}{c}\text { 6. Develop therapeutic exercise } \\
\text { program }\end{array}$ & 76 & 22 & 2 & 26 & 73 & 1 & $<.001$ \\
\hline $\begin{array}{l}\text { 7. Plan postural drainage } \\
\text { positions }\end{array}$ & 38 & 51 & 11 & 14 & 69 & 17 & NS \\
\hline $\begin{array}{l}\text { 8. Select ultrasound } \\
\text { method/settings }\end{array}$ & 52 & 45 & 3 & 32 & 65 & 3 & $<.001$ \\
\hline 9. Design ADL plan of care & 55 & 40 & 5 & 28 & 66 & 6 & $<.01$ \\
\hline $\begin{array}{l}\text { 10. Plan massage } \\
\text { method/technique }\end{array}$ & 64 & 33 & 3 & 36 & 59 & 6 & $<.001$ \\
\hline $\begin{array}{r}\text { 11. Determine solutions to } \\
\text { architectural barriers }\end{array}$ & 68 & 22 & 11 & 48 & 41 & 11 & NS \\
\hline 12. Modify treatment techniques ${ }^{c}$ & 91 & 8 & 1 & 72 & 26 & 3 & NS \\
\hline $\begin{array}{l}\text { 13. Recommend solutions to } \\
\text { architectural barriers }\end{array}$ & 89 & 6 & 5 & 89 & 7 & 4 & NS \\
\hline $\begin{array}{l}\text { 14. Prepare patient, equipment, } \\
\text { treatment area }\end{array}$ & 98 & 2 & 0 & 98 & 1 & 1 & $<.05$ \\
\hline
\end{tabular}

" $\mathrm{Y}=$ yes, designated physical therapist assistant (PTA) role; $\mathrm{N}=$ no, not designated PTA role; $\mathrm{DK}=$ do not know. Responses rounded to nearest whole percentage; missing values disregarded. $\mathrm{ADL}=$ activities of daily living; $\mathrm{NS}=$ not significant.

Thlysical therapist (PT) responses from Robinson et al. ${ }^{15}$

'Identified in reference documents as a PTA role.

Similarly, about two thirds of the PTAs thought that performance of oral sensorimotor treatment programs was a documented PTA role and an even greater number of PTs $(81 \%)$ shared that perspective.

\section{Responses on Physical Therapist Assistant Roles in Administrative Activities}

Sixteen of the activity items described administrative functions commonly associated with the operation of physical therapy services. The responses of survey participants to PTAs' roles in this category of items are summarized in Table 5. Responses to five items ("select capital equipment to be pur- chased," "plan PT staff development program," "develop PT polices/procedures," "develop quality assurance plan," and "develop space management program") differed between PTA and PT participants. For each of these items, more PTAs viewed the activity as consistent with PTA guidelines than did PTs.

The first four items listed in Table 5 were determined from a review of the references ${ }^{4,5,7-14}$ to be designated tasks for PTAs. Most PTAs $(>74 \%)$ and PTs $(>79 \%)$ concurred with this perspective. The remaining 12 administrative activities have not been explicitly identified as PTA roles. A review of the response patterns to 11 of these items ("select capital equipment to be purchased," "design fiscal management system," "manage PTA recruitment, employment, dismissal," "plan PT staff development program," "develop PT policies/procedures," "manage physical therapy aide recruitment employment, dismissal," "develop quality assurance plan," "develop space management plan," "develop clinical research project," "conduct clinical research project," and "delegate treatment tasks to an aide") reveals a general lack of consensus regarding PTAs' roles both among PTAs and between PTAs and PTs. The PTAs consistently demonstrated a higher level of support for PTA performance of these 12 administrative functions than did PTs in our prior study. ${ }^{15}$ The majority of PTAs and PTs (85\% and $70 \%$, respectively) believed that delegation of treatment tasks to an aide is a documented PTA role, yet no documentation supports this perspective.

\section{Factors Influencing the Pattern of Responses}

In general, respondent characteristics such as years of clinical experience, gender, highest earned academic degree, and primary site of current practice were not related to the pattern of PTA responses to activity items. Whether information on the scope of PTA practice was included in the PTAs' entry-level curriculum also was not related to the pattern of responses of PTAs to activity items, largely because $94 \%$ of the sample received such information. The PTAs were also asked to indicate whether they independently performed initial evaluations of patients referred for physical therapy services. Ninety-nine percent of respondents indicated that they never performed initial evaluations. Interestingly, however, 23\% stated that they did independently plan physical therapy treatment programs for at least some patients, and 28\% indicated that they independently established shortor long-term goals for physical therapy treatment programs. Discriminant analyses revealed that those who indicated that they do independently plan physical therapy treatment pro- 
Table 4. Comparison of Responses to Treatment Implementation Items ${ }^{a}$

\begin{tabular}{|c|c|c|c|c|c|c|c|}
\hline \multirow[b]{2}{*}{ Activity } & \multicolumn{3}{|c|}{$\begin{array}{l}\text { Percentage of } \\
\text { PTA Responses } \\
(n=225)\end{array}$} & \multicolumn{3}{|c|}{$\begin{array}{l}\text { Percentage of } \\
\text { PT Responses } \\
(\mathrm{n}=221)^{b}\end{array}$} & \multirow[b]{2}{*}{ Pcorr } \\
\hline & $\mathbf{Y}$ & $\mathbf{N}$ & DK & $\mathbf{Y}$ & $\mathbf{N}$ & DK & \\
\hline $\begin{array}{l}\text { 1. Administer therapeutic } \\
{\text { heat } / \text { cold }^{C}}^{C}\end{array}$ & 100 & 0 & 0 & 99 & 1 & 0 & $<.001$ \\
\hline 2. Perform therapeutic massage ${ }^{c}$ & 99 & 1 & 0 & 99 & 1 & 1 & NS \\
\hline 3. Assist in $A D L$ training ${ }^{C}$ & 98 & 1 & 1 & 99 & 1 & 0 & NS \\
\hline 4. Measure/adjust canes/crutches ${ }^{c}$ & 100 & 0 & 0 & 97 & 2 & 1 & NS \\
\hline 5. Execute therapeutic exercise ${ }^{c}$ & 100 & 0 & 0 & 98 & 1 & 1 & NS \\
\hline 6. Administer electrotherapy ${ }^{c}$ & 99 & 1 & 0 & 97 & 2 & 1 & NS \\
\hline $\begin{array}{l}\text { 7. Execute fine motor dexterity } \\
\text { exercise program }\end{array}$ & 94 & 4 & 3 & 96 & 3 & 1 & NS \\
\hline $\begin{array}{l}\text { 8. Respond to acute changes in } \\
\text { physiological state }{ }^{\circ}\end{array}$ & 97 & 0 & 2 & 95 & 5 & 1 & NS \\
\hline 9. Apply dressings/supports ${ }^{C}$ & 99 & 0 & 1 & 95 & 3 & 2 & NS \\
\hline 10. Administer gait training ${ }^{c}$ & 100 & 0 & 0 & 99 & 1 & 0 & NS \\
\hline $\begin{array}{l}\text { 11. Perform breathing reeducation } \\
\text { exercises }^{\complement}\end{array}$ & 92 & 5 & 4 & 95 & 2 & 3 & NS \\
\hline 12. Administer therapeutic traction ${ }^{\circ}$ & 99 & 1 & 0 & 95 & 4 & 1 & NS \\
\hline 13. Administer postural drainage ${ }^{c}$ & 96 & 3 & 1 & 92 & 4 & 4 & NS \\
\hline $\begin{array}{l}\text { 14. Perform intermittent venous } \\
\text { compression techniques }^{\circ}\end{array}$ & 78 & 11 & 11 & 75 & 14 & 11 & NS \\
\hline 15. Perform prosthetic training ${ }^{C}$ & 94 & 4 & 2 & 80 & 14 & 6 & NS \\
\hline $\begin{array}{l}\text { 16. Instruct patient/family in } \\
\text { treatment-related activities }\end{array}$ & 99 & 1 & 0 & 82 & 14 & 4 & NS \\
\hline $\begin{array}{l}\text { 17. Perform sensory reeducation } \\
\text { stimulation }\end{array}$ & 96 & 2 & 2 & 95 & 4 & 1 & NS \\
\hline $\begin{array}{l}\text { 18. Conduct prepartum/postpartum } \\
\text { exercise program }\end{array}$ & 73 & 12 & 15 & 71 & 15 & 15 & NS \\
\hline 19. Perform perceptual training & 92 & 5 & 4 & 90 & 5 & 5 & NS \\
\hline 20. Perform wound debridement ${ }^{c}$ & 93 & 5 & 1 & 82 & 14 & 4 & NS \\
\hline $\begin{array}{l}\text { 21. Admin neurodevelopmental } \\
\text { treatment sessions }\end{array}$ & 91 & 3 & 6 & 88 & 8 & 5 & NS \\
\hline 22. Fabricate adaptive equipment ${ }^{c}$ & 60 & 27 & 13 & 51 & 32 & 17 & NS \\
\hline $\begin{array}{l}\text { 23. Administer biofeedback } \\
\text { treatments }^{\circ}\end{array}$ & 76 & 9 & 15 & 73 & 16 & 10 & NS \\
\hline $\begin{array}{l}\text { 24. Perform oral sensorimotor } \\
\text { treatment }\end{array}$ & 66 & 15 & 19 & 81 & 11 & 8 & NS \\
\hline $\begin{array}{l}\text { 25. Measure/fit compression } \\
\text { garments }\end{array}$ & 68 & 20 & 12 & 35 & 48 & 17 & $<.01$ \\
\hline
\end{tabular}

"Y=yes, designuted physical therupist assistant (PTA) role; $\mathrm{N}=$ no, not clesignated PTA role; $\mathrm{DK}=\mathrm{do}$ not know. Responses rounded to nearest whole percentage; missing values disregarded. $\mathrm{ADL}=$ activities of daily living; $\mathrm{NS}=$ not significant.

"Physical therapist (PT) responses from Robinson et al. ${ }^{15}$

'Identified in reference documents as a PTA role.

grams were more likely to respond that four activities (ie, "design patient plan of care" [Wilk's lambda $=89$, $\left.\chi^{2}(3)=25.19, P<.001\right]$, "select electrotherapy method/settings" [Wilk's lamb- $\left.\mathrm{da}=.91, \chi^{2}(3)=18.86, P<.001\right]$, "select traction methods/settings" [Wilk's lambda $\left.=.87, \chi^{2}(3)=28.86, P<.001\right]$, and "interpret joint integrity tests" [Wilk's lambda $=91, \chi^{2}(3)=19.55$,
$P<.001])$ were documented roles of the PTA. No other demographic characteristics consistently predicted response patterns.

\section{Discussion}

\section{Perceptions of Physical Therapist Assistant Roles in Evaluation}

Definition and Utilization of the Physical Therapist Assistant (HOD $06-88-14-25), 7$ the HOD policy in effect during the time of distribution of the survey instrument, addresses the issue of the PTA's role in evaluative activities. This policy stated that the PTA shall not perform "physical therapy initial and re-evaluation ...(or)...final discharge assessment/evaluation...(or)...techniques beyond the skill and knowledge of the physical therapist assistant." The Evaluative Criteria for Accreditation of Education Programs for the Preparation of Physical

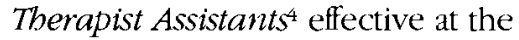
time of distribution of the questionnaire identifies only the performance of goniometric measurement and identification of architectural barriers as evaluative functions of PTA education program graduates. A recent revision of the PTA program evaluative criteria ${ }^{5}$ (effective July 1994) provides a much expanded list of assessment and measurement techniques to be included in PTA entry-level curricula. This new document indicates that PTA students shall be expected to perform techniques to assess or measure strength; endurance; flexibility; posture; balance; gait; functional activities; skin and sensation; pain; righting and equilibrium reactions; vital signs; and segmental length, girth, and volume as well as the previously denoted joint ROM and architectural and environmental barriers. Several of these recently "added" evaluative activities had previously appeared in the 1981 version of this policy (HOD 06-81-13-45), which had explicitly identified "performance, without interpretation, of selected measurement procedures such as...gross strength of muscle groups, length and girth of body parts, and vital signs." 7 These statements formed the basis for establishing PTA roles in the area of patient evaluation. 
Table 5. Percentage of Responses to Administration Activity Items"

\begin{tabular}{|c|c|c|c|c|c|c|c|}
\hline \multirow[b]{2}{*}{ Activity } & \multicolumn{3}{|c|}{$\begin{array}{l}\text { Percentage of } \\
\text { PTA Responses } \\
(n=225)\end{array}$} & \multicolumn{3}{|c|}{$\begin{array}{l}\text { Percentage of } \\
\text { PT Responses } \\
(\mathbf{n}=\mathbf{2 2 1})^{\mathrm{b}}\end{array}$} & \multirow[b]{2}{*}{ Pcorr } \\
\hline & $\mathbf{Y}$ & $\mathbf{N}$ & DK & $\mathbf{Y}$ & $\mathbf{N}$ & DK & \\
\hline 1. Perform equipment maintenance ${ }^{c}$ & 78 & 14 & 8 & 87 & 8 & 5 & NS \\
\hline $\begin{array}{l}\text { 2. Participate in quality assurance } \\
\text { program }^{c}\end{array}$ & 89 & 5 & 4 & 79 & 15 & 5 & NS \\
\hline 3. Order supplies from vendors ${ }^{c}$ & 84 & 11 & 4 & 80 & 13 & 7 & NS \\
\hline $\begin{array}{l}\text { 4. Plan PTA staff development } \\
\text { program }^{c}\end{array}$ & 74 & 17 & 9 & 85 & 10 & 5 & NS \\
\hline $\begin{array}{l}\text { 5. Manage PT recruitment, } \\
\text { employment, dismissal }\end{array}$ & 9 & 81 & 9 & 1 & 98 & 2 & NS \\
\hline $\begin{array}{l}\text { 6. Select capital equipment to be } \\
\text { purchased }\end{array}$ & 37 & 42 & 22 & 18 & 63 & 20 & $<.010$ \\
\hline 7. Design fiscal management system & 28 & 48 & 24 & 16 & 63 & 21 & NS \\
\hline $\begin{array}{l}\text { 8. Manage PTA recruitment, } \\
\text { employment, dismissal }\end{array}$ & 30 & 56 & 14 & 24 & 66 & 11 & NS \\
\hline $\begin{array}{l}\text { 9. Plan PT staff development } \\
\text { program }\end{array}$ & 17 & 66 & 17 & 9 & 84 & 8 & $<.05$ \\
\hline 10. Develop PT policies/procedures & 42 & 40 & 18 & 16 & 71 & 13 & $<.001$ \\
\hline $\begin{array}{l}\text { 11. Manage physical therapy aide } \\
\text { recruitment, employment, } \\
\text { dismissal }\end{array}$ & 41 & 46 & 14 & 28 & 61 & 12 & NS \\
\hline 12. Develop quality assurance plan & 57 & 30 & 14 & 41 & 46 & 13 & $<.001$ \\
\hline $\begin{array}{l}\text { 13. Develop space management } \\
\text { program }\end{array}$ & 51 & 24 & 26 & 37 & 39 & 25 & $<.001$ \\
\hline 14. Develop clinical research project & 52 & 29 & 19 & 44 & 39 & 17 & NS \\
\hline 15. Conduct clinical research project & 54 & 27 & 20 & 49 & 33 & 18 & NS \\
\hline $\begin{array}{l}\text { 16. Delegate treatment tasks to an } \\
\text { aide }\end{array}$ & 85 & 13 & 2 & 70 & 23 & 7 & NS \\
\hline
\end{tabular}

" $\mathrm{Y}=$ yes, designated physical therapist assistant (PTA) role; $\mathrm{N}=\mathrm{no}$, not designated PTA role; $\mathrm{DK}=\mathrm{do}$ not know. Responses rounded to nearest whole percentage; missing values disregarded. $\mathrm{NS}=$ not significant.

'Physical therapist (PT) responses from Robinson et al. ${ }^{15}$

'Designated by authors as a defined role of the PTA

Lupi-Williams ${ }^{11}$ addressed the issue of "What the PTA Is Not" and focused this discussion on the process of patient evaluation, noting, by definition, that evaluation entailed both examination and judgment. Although examination could be interpreted as the performance of routine testing procedures, judgment implies that decisions must be made regarding choice of procedures and interpretation of the results, which requires knowledge of complicated scientific theory. Lupi-Williams suggested that in the early 1980s, PTAs did not have the requisite knowledge base to validate extensive involvement in evaluative activities, remarking that "evaluating patients...remain(s) the responsibility of the physical therapist."11(p38)

Of those six evaluation activities determined to be documented PTA functions, only one activity, "perform joint ROM tests," was found to have response patterns that were noteworthy. Only $45 \%$ of the PTAs and $31 \%$ of the PTs thought that ROM testing was a documented PTA role. Such responses suggest the possible underutilization of PTAs in the performance of ROM testing. Performance of goniometric measurement has specifically been identified in reference documents applicable for over 15 years as an expectation of the PTA graduate.4

For eight of the evaluative activities, PTAs and P'Ts had different patterns of response. These activities were "determine prosthetic/orthotic/assistive device," "interpret joint integrity tests," "interpret developmental tests," "test accessory joint motions," "interpret joint ROM tests," "perform specific manual muscle testing," "assess muscle tone," and "determine wheelchair type/features." For each of these items, substantially higher percentages of PTAs than PTs viewed these functions as documented PTA tasks. Although none of these activities had been explicitly identified in P'TA guideline documents effective at the time of survey distribution, certain components of these evaluative functions such as assessment of posture, flexibility, righting and equilibrium reactions, functional activities, and muscle strength have been identified (item 3.2.2.4) in the recently revised PTA program evaluative criteria. ${ }^{5}$ Both PTAs and PTs, 86\% and 95\%, respectively, believed that the performance of sensory evaluations was not a documented PTA role at the time of the survey. Although that belief was consistent with applicable documentation, newly adopted education criteria indicate that performance of assessment and measurement techniques of skin and sensation are expected of the entry-level PTA. ${ }^{5}$ Both PTAs and PTs should become aware of these changes in PTA activities to avoid potential underutilization of PTAs in the performance of these evaluative procedures.

\section{Perceptions of Physical Therapist Assistant Roles in Treatment Planning}

The APTA HOD policy statement on PTA utilization approved in 1988 (HOD 06-88-14-25) states that the PTA shall not perform "identification, determination, or modification of plans of care including goals and treatment programs."7 The latest version of this policy, adopted in 1993 and included within the policy statement "Direction, Delegation, and Su- 
pervision in Physical Therapy Services," indicates that development and modification of plans of care is a responsibility of the PT. These statements formed the basis for establishing PTA roles in the area of treatment planning.

Three treatment planning activities"recommend solutions to architectural barriers," "modify treatment techniques," and "prepare patient, equipment, treatment area"-were found to be PTA functions consistent with existing PTA guidelines. Most PTAs and PTs agreed that these three activities were included in documents outlining PTA practice.

Responses of PTAs and PTs differed for four of the treatment planning activities (ie, "develop therapeutic exercise program," "select ultrasound method/settings," "design ADL plan of care," and "plan massage method/ technique"). Approximately one half to three quarters of the PTAs indicated that these functions were consistent with PTA role guidelines. In contrast, only about one quarter to one third of PTs shared this perspective. Such a finding may indicate that PTAs generally desire to work under plans of care that leave some of the decision making regarding treatment guidelines in their hands, whereas PTs may generally want to design a more prescriptive plan of care that is simply implemented by the PTA.

An interesting finding related to the item "design patient plan of care" occurred. Although only $16 \%$ of the PTAs viewed this activity as a documented PTA role, 23\% of the PTAs indicated that they "independently plan physical therapy treatment programs" for some patients. Thus, a substantial percentage of PTAs are actually performing treatment planning when in fact they do not believe this activity is an appropriate PTA role.
Physical Therapists' Perceptions of Physical Therapist Assistant Roles in Treatment Implementation

In general, most routine physical therapy treatment procedures have been clearly identified in reference documents ${ }^{1,5,7-14}$ as PTA roles. A review of the data regarding treatment implementation activities indicates that the PTA and PT respondents shared this perspective (Tab. 3)

Five of the treatment activities (ie, "perform sensory reeducation stimulation," "perform perceptual training," "perform neurodevelopmental treatment session," "perform oral sensorimotor treatment," and "measure/fit compression garments") were not identified in reference documents as PTA roles. Most PTAs (66\%-96\%), however, believed that these activities have been documented as appropriate PTA roles. The PTs responding in 1992 shared these opinions, except for the PTA's involvement in fitting compression garments; only $35 \%$ of the PTs thought this activity to be a documented PTA role. These data would lend support to those advocating revision and expansion of PTA guidelines regarding the treatment implementation roles of the PTA.

Some might argue that any type of treatment within the domain of physical therapy is an appropriate function of the PTA because APTA guidelines generally suggest that the PTA's role is to provide treatment following evaluation and development of a plan of care by a PT. Others might maintain that the safe and effective implementation of some treatment procedures may require a level of knowledge in the basic sciences (eg, anatomy, neurosciences) that is well beyond the educational preparation of the PTA and, hence, should not fall within the scope of PTA practice. Debate on this issue may be of value in clarifying the role of PTAs in providing treatment and may lead to more effective treatment of those receiving physical therapy services.

\section{Physical Therapists' Perceptions of Physical Therapist Assistant Roles in Administration}

Information on the role(s) of PTAs in activities designated as administrative is lacking in documentation regarding PTA duties and responsibilities. The policy on definition and utilization of the PTA (HOD 06-88-14-25) notes that "where permitted by law, the physical therapist assistant may carry out routine operational functions including supervision of the physical therapy aide and documentation of treatment progress." Evaluative criteria for PTA education programs ${ }^{4}$ have indicated that the entry-level P'TA should "understand the basic concepts related to...quality care,...role of other health care providers, (and)... health care facilities." Physical therapist assistant graduates are also expected to "understand basic principles of levels of authority, planning time management, supervisory process,... policies and procedures, and fiscal consideration."

Only four activities ("perform equipment maintenance," "participate in quality assurance program," "order supplies from vendors," and "plan PTA staff development program") were designated as documented PTA roles. The majority of PTAs and PTs concurred with this perspective. Most PTAs (85\%) and PTs (70\%) also indicated that delegation of treatment tasks to an aide was a documented PTA role. Although supervision of an aide does appear in documents outlining PTA functions, APTA policy on the direction and supervision of physical therapy services (HOD 06-83-08-09)7 indicates that delegation of the services to be rendered by the PTA or other supportive personnel is the sole responsibility of the $\mathrm{PT}$. If such an interpretation is valid, then participant responses to this item were incongruent with policy regarding PTA practice.

The responses of PTAs in this study and those of PTs in our previous study $^{15}$ reveal a lack of consensus regarding whether 10 "administrative" activities (ie, "select capital equipment 
to be purchased," "design fiscal management system," "manage PTA recruitment, employment, dismissal," "plan PT staff development program," "develop PT policies/procedures," "manage physical therapy aide recruitment, employment, dismissal," "develop quality assurance program," "develop space management program,"

"develop clinical research project," and "conduct clinical research project") are documented PTA roles. For five of these activities (ie, "select capital equipment to be purchased," "plan PT staff development program," "develop PT policies/procedures," "develop quality assurance plan," and "develop space management program"), PTA and $\mathrm{PT}$ response profiles were different. For each of these items, more PTAs viewed these activities as documented PTA roles than did PTs.

The lack of consensus among responding PTs and PTAs regarding PTA involvement in many of the administrative functions indicates the need for such activities to become the focus of future discussion on PTA role delineation.

\section{Significance of the Research}

This study represents the first nationwide survey of PTAs in over 15 years designed to gain insight into their perceptions of the documented roles of the PTA. Previous investigations into the clinical functions of PTAs have been limited to regional investigations, ${ }^{18}$ often in association with the graduates of a single institution ${ }^{17}$ or a few selected PTA education programs. $^{16}$

Optimal delivery of physical therapy services requires optimal use of all physical therapy personnel. Optimal utilization of PTAs in physical therapy requires that PTs and PTAs have congruent perceptions of role delineation. The data presented from this study indicate that PTs and PTAs who are members of APTA have similar perceptions of PTA performance for most activities, but certainly not all. This study illustrates where PT and PTA perceptions of PTA roles differ, and this information may be used to focus discussion in future efforts regarding appropriate utilization of the PTA. Our results reflect a sample of PTAs who are APTA members. Our discussion of PT attitudes is also based on APTA members. Attitudes and behavior of non-APTA member PTs and PTAs may differ and should be the focus of future research.

Physical therapists who supervise the activities of PTAs may find the results of this study valuable as they consider what tasks to delegate to the PTA. An understanding of PTA opinions on PTA roles may allow the supervising therapist to employ the PTA more efficiently in patient evaluation and treatment. The assignment of selected administrative tasks to the PTA may allow the supervising therapist more time for involvement in more complex evaluative procedures and planning of treatment programs. Assignment of duties to the PTA that are more consistent with their perceptions (and education) may also reduce PTA job dissatisfaction and foster better professional communication. Finally, faculty responsible for the education of both PT and PTA students should find the information from this study valuable in their discussions of the supervisory relationship between the PT and the PTA.

\section{Summary}

The purposes of our study were to determine PTA perceptions of the roles of the PTA and to compare their perceptions with those of PTs who participated in a similar study. The results illustrated considerable agreement between PTAs and P'Ts regarding the documented roles of the PTA. Physical therapist assistants and PTs had different perceptions of documented PTA roles for approximately $25 \%$ of the activities included in the questionnaire. In general, a higher percentage of PTAs than PTs viewed activities as consistent with the scope of practice regardless of whether the activity was clearly a documented PTA role. Only for the treatment implementation activities did both PTAs and PTs have perceptions of PTA roles that exceeded those outlined in reference documents. Physical therapist assistant and PT opinions were different for approximately one third of the activities in the evaluative, treatment planning, and administrative categories. The data derived from this study may be useful in focusing discussions on PTA guidelines as well as PT and PTA education content.

\section{References}

1 Occupational Outlook Handbouk Washington, DC: Bureau of Labor Statistics, US Department of Labor; 1990

2 Physical Therapist Assistant Programs. Alexandria, Va: Department of Fclucation/Rc-

search, American Physical Therapy

Association; December 1993.

3 Woods E. PTAs: history and developnlent. PT-Magazine of Physical Therapy. 1993;1(4): $34-39$.

4 Commission on Accreditation in Physical Therapy Education. Evalnative Criteria for Accreditation of Edacation Programs for the Preparation of Physical Therapist Assistants. Alexandria, Va: American Physical Therapy Association; adopted 1978, renamed and revised 1990

5 Commission on Accreditation in Physical Therapy Education. Evaluative Criteria for Accreditation of Education Programs for the Preparation of Pbysical Therapist Assistants With Interpretive Comments and Guidelines. Alexandria, Va: American Physical Therapy Association; adopted February 1993, effective July 1994

6 Commission on Accreditation in Physical Therapy Education. Eiculuative Criteria for Accreditation of Education Programs for the Preparation of Physical Therapists. Alexandria, Va: American Physical Therapy Association; adopted 1990, effective 1992.

7 Definition and Utilization of the Physical Therapist Assistant (HOD 06-93-08-09). In: Minutes of the 1993 House of Delegates Meeting. Alexandria, Va: American Physical Therapy Association; 1993. (Previously HOD 0681-13-45 and HOD 06-88-14-25.)

8 Competencies in Physical Therapy: An Analysis of Practice. 2nd ed. San Diego. Calif: Courseware Inc; 1979. Lipdated 1981, 1983 , 1985.

9 Standarels of Ethical Conduct for the Physical Therapist Assistant. In: Minutes of the 1982 House of Delegates Meeting. Alexandria, Va: American Physical Therapy Association; 1982.

10 Guide for Ethical Conduct of the Afjiliate Member. Alexandria, Va: Judicial Comnittee, American Physical Therapy Association; October 1981, amended 1989.

11 Lupi-Williams FA. The PT'A role and function, part 1: education. Clinical Management in Pbysical Therapy. 1983:3(3):35-38.

12 James $S$. The PTA role and function, part 2: use of the PTA in a general practice setting-a PTA's response. Clinical Management in Pbysical Therapy. 1983:3(3):38-39. 
13 Murphy P. The PTA role and function, part 3: a job description. Clinical $M$ an agement in Physical Therapy. 1983:3(33:39- 40.

14 Carpenter CA. PTA career ladder. PTM agazine of Physical Therapy. 1993;1(1):5661

15 Robinson AJ, McCall M, DePalma MT, et al. Physical therapists' perceptions of the roles of the physical therapist assistant, Phys Ther. 1994;74:571-582.
16 Gossett RL. A ssistant utilization: a pilot study. Phys Ther. 1973;53:502-506.

17 Larson CW, Davis HR. Following up the physical therapist assistant graduate: a curriculum evaluation process. Phys Ther. 1975;55: 601. 606

18 Schunk C, Lippert L, Reeves B. PTA practice: in reality. Clinical $M$ anagement. 1992; 12(6):88-94.
19 Glass GV, McGaw B, Smith ML. M etaanalysis in Social Research. Beverly Hills, Calif: Sage Publications Inc; 1981.

20 Kenny DA. Statisticsfor the Social and B ehavioral Sciences. Boston, Mass: Little, Brown and Company Inc; 1987.

21 Darlington RB. Regression and Linear M odels. New York, NY: McGraw-Hill Inc; 1990 